\title{
Management Occupations
}

National Cancer Institute

\section{Source}

National Cancer Institute. Management Occupations. NCI Thesaurus. Code C97639.

A class of professional or vocational positions of employment that involve management. 